\title{
Cough and sleep in inner-city children
}

\author{
P. Fuller, A. Picciotto, M. Davies, S.A. McKenzie
}

Cough and sleep in inner-city children. P. Fuller, A. Picciotto, M. Davies, S.A. McKenzie. CERS Journals Ltd 1998.

ABSTRACT: This study aimed to determine whether cough at night keeps children awake, to describe the relationship between children's cough and sleep and to report parents' perceptions of their children's cough and sleep.

Thirty-nine children with reported persistent cough at night ( $>3$ weeks) were recruited and studied for 6 nights by video-recording. Coughs were counted and sleep state was coded for awake, restless sleep and quiet sleep. The relationships between cough and sleep state between subjects and within subjects were examined by correlation and regression. After night 2 the parents were asked whether their child had coughed or had disturbed sleep and after night 6 they were asked whether there had been any change.

There was a weak relationship between log percentage of the night awake and log number of coughs $(r=0.13$, sE 0.036$)$, and $\log$ (percentage of the night awake plus restless sleep) and log number of coughs $(\mathrm{r}=0.016, \mathrm{sE} 0.0071)$. If the relationship between cough and sleep state is causal, halving the number of coughs will reduce the percentage of the night awake by $9 \%$ (95\% confidence interval (CI) 4-15\%) and percentage awake and restless by $1 \%(95 \%$ CI 0-2\%). All but one parent correctly identified coughing and $82 \%$ detected change. Most could not comment on their child's sleep.

Improvement in cough would result in little reduction in either the percentage of the night awake or awake and restless in the average child in the population studied. Parents could detect whether their children were coughing but not whether their sleep was disturbed.

Eur Respir J 1998; 12: 426-431.

Major epidemiological studies of asthma in childhood in the 1960s [1, 2] used in their questionnaires the presence of wheeze as the only symptom upon which the diagnosis of asthma was made. Neither cough nor night-time symptoms were mentioned. In a recent editorial about the epidemiology of asthma [3] the definition of asthma once more included only "wheeze". However, in an international consensus document (1992) asthma was defined as "recurrent wheeze and/or cough" [4]. More recent guidelines have stated "criteria for defining asthma in the presence of chronic or recurrent cough have not been adequately defined" [5]. The relationship between cough and asthma continues to be debated $[6,7]$. Recent reports suggest that clinical and epidemiological aspects of isolated persistent cough in childhood differ from those of childhood asthma $[8,9]$ and only the minority of night-time coughers turn out to have asthma [10].

This debate is important if it is considered appropriate to treat isolated persistent cough with asthma medication. Even children who cough but also wheeze and are therefore considered asthmatic seem to derive no benefit from bronchodilators as far as the cough is concerned [11]. Parents' main concern is about loss of sleep, both their child's and their own [12]. If a child's sleep is affected, either in quantity or quality, then it is reasonable to identify a treatment which will help.

Parents are proxy reporters of their children's symptoms. However, when coughing recorded by audiotape is com-
Queen Elizabeth Hospital for Children, London, UK.

Correspondence: S.A. McKenzie

Queen Elizabeth Hospital for Children

Royal Hospitals Trust

Hackney Road

London E2 8PS

UK

Fax: 441716086425

Keywords: Asthma

cough

sleep

Received: December 291997

Accepted after revision April 141998

Supported by GlaxoWellcome and the Queen Elizabeth Hospital for Children Research Fund pared with diary entries, neither parents $[13,14]$ nor patients [15] can quantify coughing. Parental documentation of children's sleep behaviour has also been shown to be inaccurate $[16,17]$.

Previous studies of young children's sleep conducted in the home have used video recordings to monitor the sleep/ wake cycle [18]. Audiovideo methods have the benefit of recording symptoms such as cough in environments not suitable for sound only, such as those where children are sharing a room or bed. Video recording helps to identify the source of the sound.

The main purpose of this study was to describe the relationship between cough and sleep state. If the relationship between cough and sleep disturbance is strong then it would be reasonable to propose that cough causes the disturbance. Treatment likely to benefit persistent nocturnal cough could also benefit sleep. The second purpose of this study was to report whether parents who complain that their children cough persistently at night can accurately identify whether their child is coughing on a particular night and can judge changes in cough and sleep.

\section{Methods}

\section{Subjects}

Children from an inner-city area whose parents said they coughed at night were recruited to the project through 
general practitioner (GP) referral and from ambulatory patients attending this hospital. GPs in east London were asked to refer children with persistent cough without other symptoms or signs. Persistent nocturnal cough (PNC), as reported by parents, was defined as coughing at night for $>3$ weeks. Investigations such as chest radiographs were undertaken when clinically indicated. Consecutive families with aged children 1-10 yrs with PNC were approached. Children with current upper respiratory tract infection, a history of wheeze or fever or an identifiable cause for their cough, such as whooping cough, persistent nasal discharge or large tonsils were excluded.

\section{Questionnaire}

Subjects and/or their parents completed a questionnaire which recorded demographic data. Also recorded were the time at which the child had had the cough and whether parents believed it had disturbed sleep. The questionnaire asked what worried parents about the cough, whether it was life-threatening disease, choking, asthma, permanent chest damage or another worry. All but the last question were closed questions.

\section{Equipment}

Subjects were video recorded as they slept at home using a time-lapse recorder (Panasonic Ag-6040), a camera with infra-red light (JVC TK-S240E) and microphone [19]. Recordings were made in linear $24 \mathrm{~h}$ mode, recording every eighth frame. This allowed each night's sleep to fit easily on to one $3 \mathrm{~h}$ tape. The equipment was set up close to the child's bed or cot to allow a view of the child asleep. It was important to see the face and eyes. Parents or older siblings were shown how to start and stop recordings and how to change the videotapes.

\section{Diary}

A diary with a set format, similar to an asthma diary, was designed for parents to record their estimate of their child's cough and sleep during the night for the period of the recordings.

\section{Pilot study}

Consecutive subjects were approached to find out whether, within the time allocated to the study, a reasonable proportion of families would agree to home studies, to ensure that equipment would not be tampered with and to enable clear definitions of cough and sleep state to be reliably coded. Of 27 subjects who met the inclusion criteria, 15 were successfully recorded for 1 night. The parents of two potential subjects refused because of the intrusion, six were not coughing at the time of request and contact was lost with four. It was calculated that recruitment of 30 subjects each year was possible. Permission for the study was obtained from the East London and City Ethics Committee.

\section{Coding of data}

Tapes were viewed manually in real time, that is, a $24 \mathrm{~h}$ recording would be watched in $3 \mathrm{~h}$. Tapes would be slowed to linear $24 \mathrm{~h}$ when areas of interest were identified, to enable accurate coding of each event. The "Observer" videotape analysis system for behavioural research (Noldus Information Technology, Tracksys, Nottingham, UK) was used for coding. Coding began when the child went to bed, whether awake or asleep, and finished when they left the bed the next morning. Codes were selected for individual coughs, coughing bouts and sleep state (awake, restless sleep and quiet sleep) based on the definitions of ANDERS [18]. The definitions for cough states (below) were based on the pilot study. They seemed to be the most practical way of categorizing coughing which seemed to be either in isolation or in clusters.

\section{Definitions}

1) Individual coughs; 2) cough bout: a series of individual coughs, with $<5$ s between each cough; 3 ) awake: eyes open, or otherwise obviously awake (e.g. sitting up, playing, talking) with $<5$ min between actions; 4) restless sleep: eyes closed, with bodily movement, with $<5$ min between movements (movement due to breathing was not included); and 5) quiet sleep: eyes closed, with no movement for $>5$ min (where eyes were not seen and there was no movement for $>5 \mathrm{~min}$, quiet sleep was assumed). Interrator reliability for these codes is $>91 \%$ [19].

Diaries were examined for the reliability of data entry. Those which were poorly kept were discarded.

\section{Main study}

The parents of all children who fulfilled the inclusion criteria completed the questionnaire, with an interpreter if needed. Parents of children were then given the opportunity to take part in the study of cough and sleep and to enrol in a randomized trial of an inhaled corticosteroid, a separate longer study. Some of the children were therefore being given corticosteroids during this study. These drugs have been prescribed for many years and have not been reported to affect sleep independently. The main purpose of the study reported here, namely the relationship between cough and sleep, would therefore not be confounded by their use. Children were receiving no other prescribed medication. The children's cough and sleep was then recorded on three occasions for 6 nights in their homes: two nights' run-in to ensure they were coughing, with a total of at least six bouts in the 2 nights, and 2 consecutive nights during each of the following 2 weeks (fig. 1). Parents were

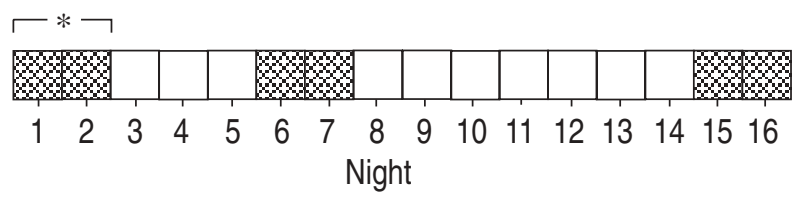

Fig. 1. - Diagram of the recording protocol (16 day study period). $\$$ : recording night. If subjects were not coughing during the run-in period (*) the study was abandoned. 
shown how to fill in the diary. After the second night each was asked whether their child had coughed or had disturbed sleep on that night. At the end of the study they were asked to say whether cough and sleep were better, the same or worse. These questions were asked to cross-check the diary entries.

\section{Analysis of data}

Data for sleep were expressed as a percentage of the total night in different sleep states, where the total night began with being put to bed and ended with getting out of bed or the end of recording. It was assumed that this time in bed is the time for which parents hope their children will fall asleep and sleep undisturbed. The number of wakings was calculated from the first time at which the child awoke from the restless or asleep state to the time of final waking, which was not included. Individual coughs and cough bouts were related to the sleep state in which these occurred. The results of descriptive data were expressed as percentages. Correlation and regression describe between-subject and within-subject relationships between cough and sleep. Both percentages in sleep states and numbers of coughs were converted to logarithms before analysis.

\section{Results}

\section{Subjects and demographic data}

Subjects fitting the inclusion criteria and their demographic data, together with the subjects eventually studied are described in table 1. On inspection of the data, potential subjects did not differ in any significant way from those studied.

\section{Worries expressed by parents}

More than one concern was often expressed (table 2). Approximately half of the subjects' parents were concerned about the effect of cough on sleep.

Table 1. - Recruitment and demographic data of the referred subjects

\begin{tabular}{lc}
\hline Fitting entry criteria & 96 \\
Sex F/M & $59 / 37(1.6: 1)$ \\
Age 1-4 yrs & 71 \\
$5-9$ yrs & 25 \\
English not first language & 29 \\
Co-sleeper/room sharer & 65 \\
Excluded* & 37 \\
Recorded 2 nights & 59 \\
Excluded & 20 \\
Total complete studies & 39 \\
Sex F/M & $25 / 14(1.5: 1)$ \\
Age 1-4 yrs & 32 \\
5-9 yrs & 7 \\
English not first language & 16 \\
Co-sleeper/room sharer & 26 \\
\hline
\end{tabular}

Data presented as number of subjects with ratios in parenthesis. F: female; M: male. *: not coughing by time seen, refusal $(n=8)$; +: faulty recordings, not coughing enough, snoring or pertussis.

\section{Recording successes}

Of the 39 subjects, 27 had 6 nights of complete recordings, eight had 5 and four had 4.

\section{Coughs and cough bouts}

Coughs are described in table 3. Coughing decreased between nights 1 and 2, and 5 and 6. Coughing occurred throughout the night for the average child. For some children it occurred only at a particular time. The sleep state from which coughing started varied but for the average child $>50 \%$ of the coughing started in quiet or restless sleep.

\section{Sleep}

The median of the mean times awake for each subject, quietly asleep and restless over the 4-6 recordings and other data for sleep are described in table 4 . The average child was awake for $<10 \%$ of the night. Fourteen subjects

Table 2. - Concerns of subjects' parents

\begin{tabular}{lcc}
\hline & $\begin{array}{c}\text { Subjects fitting } \\
\text { entry criteria } \\
\mathrm{n}=96\end{array}$ & $\begin{array}{c}\text { Subjects in } \\
\text { main study } \\
\mathrm{n}=36\end{array}$ \\
\hline Lack of sleep & 24 & 17 \\
Asthma & 19 & 11 \\
Life-threatening disease & 5 & 3 \\
Choking & 20 & 10 \\
Permanent chest damage & 11 & 9 \\
Other & 58 & 25 \\
\hline
\end{tabular}

Data presented as number of subjects.

Table 3. - Results: coughing

\begin{tabular}{lcc}
\hline & Median & Range \\
\hline Duration of recording h & 9.8 & $3.8-13.8$ \\
Total coughs & & \\
$\quad$ Nights 1 and 2 & 69 & $9-1132$ \\
$\quad$ Nights 5 and 6 & 12 & $0-324$ \\
Cough bouts & & \\
$\quad$ Nights 1 and 2 & 20 & $6-230$ \\
$\quad$ Nights 5 and 6 & 5 & $0-46$ \\
Coughs before 00:00 h \% & 33 & $0-100$ \\
Coughs between 00:00 h and 04:00 h \% & 31 & $0-100$ \\
Coughs between 04:00 h and waking \% & 35 & $0-100$ \\
Cough bouts in quiet sleep \% & 5.7 & $0-13$ \\
Cough bouts in restless sleep \% & 53.8 & $0-50$ \\
Cough bouts in awake \% & 40.5 & $0-37$ \\
\hline
\end{tabular}

Table 4. - Results: sleep

\begin{tabular}{lcc}
\hline & Median & Range \\
\hline Time to fall asleep min & 10.5 & $3.5-186$ \\
Wakings $\mathrm{n}$ & 3 & $0-13$ \\
Time asleep (quiet + restless) $\mathrm{h}$ & & \\
$\quad$ Age 1-4 yrs & 9.1 & $4.0-11.5$ \\
$\quad$ Age 5-10 yrs & 9.2 & $8.1-10.5$ \\
Mean recording time for each & & \\
$\quad$ child (4-6 recordings) \% & & \\
$\quad$ Awake & 7.8 & $1-24$ \\
$\quad$ Quiet sleep & 41 & $22-60$ \\
$\quad$ Restless sleep & 40 & $29-72$ \\
\hline
\end{tabular}


were always put to bed awake. The others were put to bed asleep on at least one occasion. The overall within-subject coefficients of variation for the awake state and for the awake plus restless state were $78 \%$ and $14 \%$

\section{Relationship between cough and sleep}

On the second night of recording the between-subject correlation coefficient for individual coughs and percentage of the night awake was $0.25, \mathrm{p}=0.13(\mathrm{n}=37)$ and for individual coughs and percentage of the night awake and restless was $0.36, p=0.03(n=37)$. The recordings of two of the 39 subjects on night 2 were unsuccessful. Examples of the relationship between cough and percentage of the night awake are shown in figure 2 . The within-subject correlation coefficient $\log \%$ awake time on log number of coughs was $0.26(\mathrm{p}=0.01 ; \mathrm{r}=0.13$, SE 0.036$)$ with a residual coefficient of variation of $74 \%$. The within-subject correlation coefficient (log \% awake time $+\%$ restless) was 0.17 ( $\mathrm{p}=0.02 ; \mathrm{r}=0.016$, SE 0.0071$)$ with a residual co-efficient of variation of $17 \%$. The regression coefficients imply that halving the number of coughs will reduce the percentage awake time on average by $9 \%$ (95\% confidence interval (CI) 4-15\%) and percentage awake and restless time by $1 \%$ (95\% CI $0-2 \%)$.

\section{Parental perception of cough}

When the video evidence on the second night's recording was compared with parents' reports, $98 \%$ parents cor-
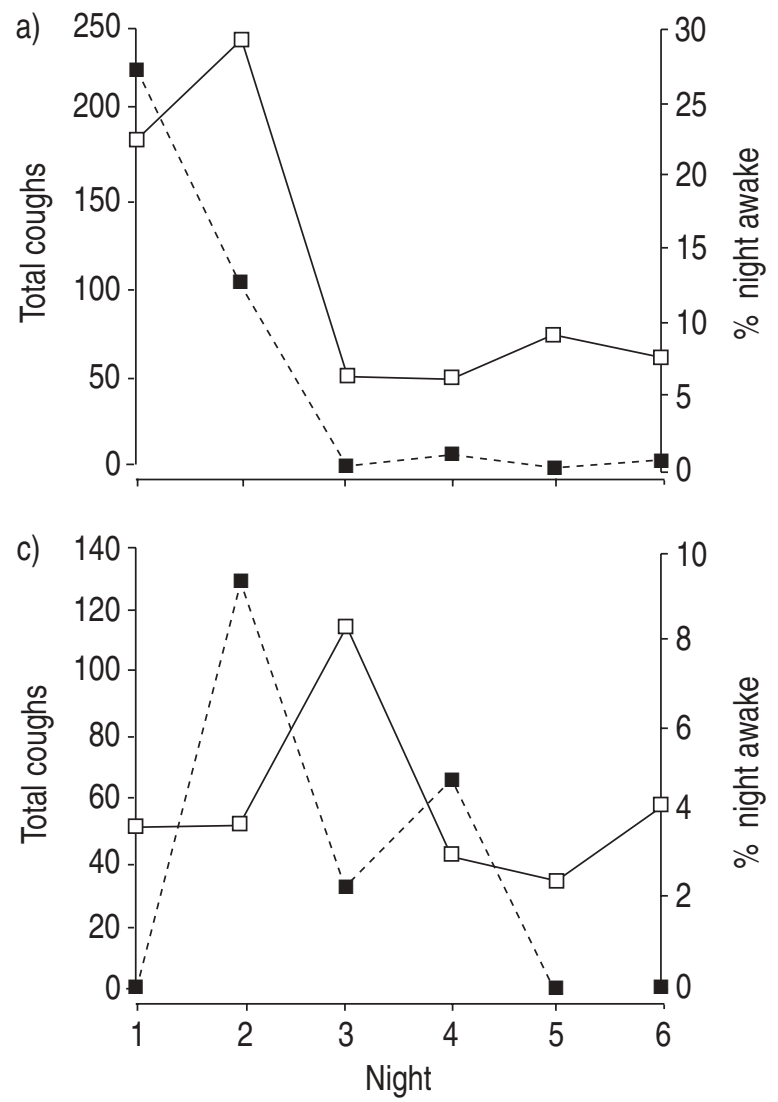

rectly perceived whether their child was coughing or not coughing. At the end of the study $82 \%$ correctly perceived whether their child was better or worse.

\section{Parental perception of sleep}

Of 19 parents who answered this question 53\% correctly perceived change. The remainder said that they did not know as they themselves were asleep.

\section{Diaries}

Only four diaries were correctly filled in and, therefore, no diaries were analysed.

\section{Discussion}

In this study consecutive subjects were recruited from referrals from family doctors in east London and from the authors' own ambulatory service. All local doctors were informed of the project so that, as far as possible, subjects representative of those in the community could be recruited. However, it was recognized that the most anxious parents or those who reported the most frequent or severe cough would probably be referred.
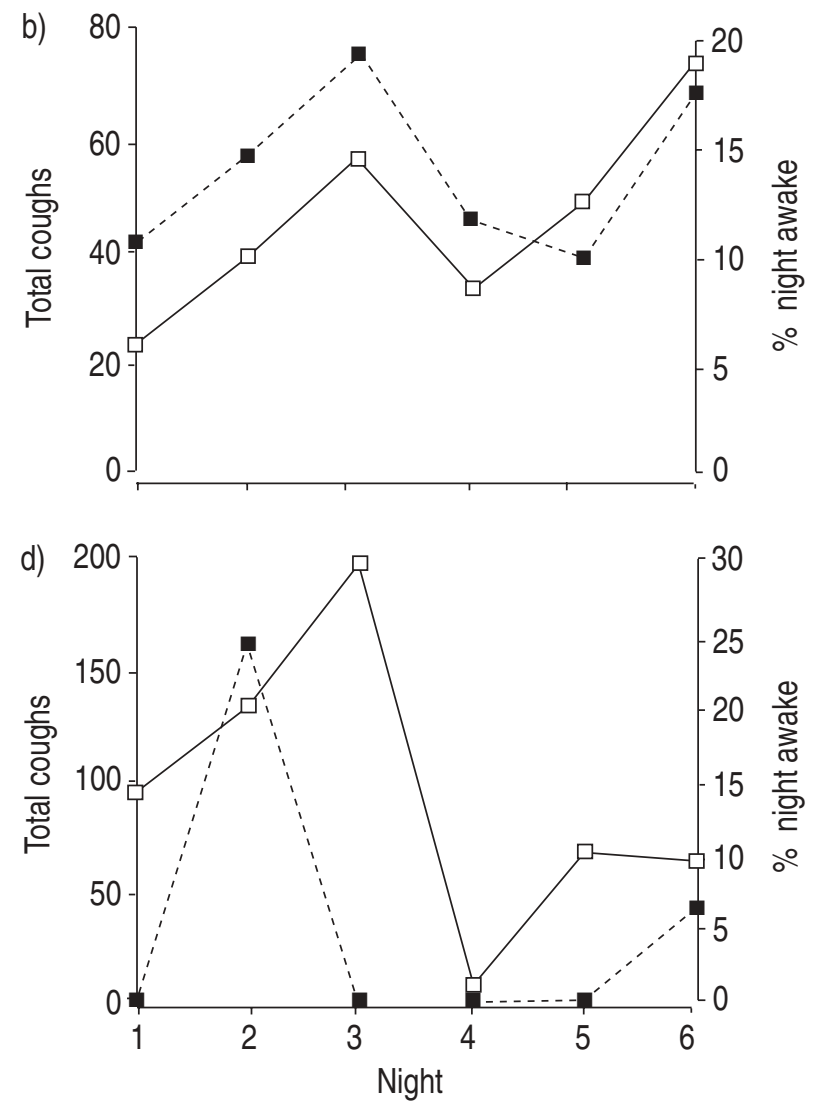

Fig. 2. - Examples of the relationship between percentage of the night awake ( $\square$ ) and total coughs (匹) on nights 1-16. a) patient 1; b) patient 2; c) patient 3 ; d) patient 4 . Patients 1 and 2 showed concordance between total coughs and percentage of the night spent awake. Patients 3 and 4 showed discordance. 
The authors' experience with video recording children in east London has previously been reported [19]. Surprisingly few potential subjects' parents refused to take part $(<10 \%$ of those asked) and those subjects studied seemed demographically representative of the total who presented with a history of persistent nocturnal cough. Therefore, the subjects reflect, as far as we can tell, those living in an inner-city population.

This study has confirmed that $50 \%$ of parents with children who have persistent night-time cough worry about their child's loss of sleep. The cognitive disturbance on the following day due to poor sleep has been well described for adults and older children as well as for this age group [20]. The within-subject coefficient of variation for percentage awake and restless was $14 \%$, suggesting that in spite of large differences in cough from night to night and in the percentage of recording time spent awake (coefficient of variation $78 \%$ ), the percentage time spent quietly asleep, i.e. everything that is not awake and restless, seemed to be reasonably stable. The time taken to fall asleep was reported to emphasize the large range in this group and the whole recording time from the time the subjects went to bed was analysed because it was felt that this represented the time at which parents would have liked their children to sleep. It is acknowledged that the shorter durations of recording could have been because parents forgot to turn the video on or did not turn it on for some other reason.

The sleep states of ANDERS [18] were used because current technology for electroencephalographic monitoring in this age group would be impractical in households where there is room-sharing and co-sleeping. In any event, it would be reasonable to assume that the events that were coded awake and restless would be similar to those that the parents perceived as awake and restless.

Coughing occurred throughout the night. Parents accurately reported whether or not their child had been coughing and most could tell whether there had been any change over the period of the study. In other words, parents could make qualitative judgements about the children's cough. This would be useful to know when recruiting subjects for a trial of treatment. Others have shown that parents and patients cannot quantify coughing when diary entries of cough are compared against cough recordings [13-15]. However, parents were unable to say whether sleep improved when the cough improved, perhaps because they themselves were asleep. Only half of those who could definitely give an answer were correct.

Does coughing occur whilst the child is already awake? Although the average child was awake for $<10 \%$ of the recording time, $40 \%$ of coughs occurred during this time. Sixty per cent of coughing occurred whilst children were either quietly asleep or restless, mainly the latter. However, the relationship between cough and being restless and awake, although statistically significant, was very weak. This suggests that the cough did not cause the children to be restless and awake.

Sleep has not previously been studied in the home in a group of unselected children and so it is not known whether the children's sleep in this study was comparable to a similar group. The main purpose of this study was to examine the relationship between cough and sleep and to describe parents' perception of change. The study by MINDE et al. [17] looked at a group of younger children from a small university town over 3 nights. A group of "good sleepers", whose parents did not complain about their sleeping, was compared using home video recordings with a group of "poor sleepers", whose parents said that their children had trouble sleeping. The mean number of wakings observed for both good and poor sleepers $<3$ yrs old was 3.2 and 3.4, which was comparable to the present median of three wakings for children aged $<5$ yrs. This suggests that waking is a behavioural element of normal sleep and is not due to something, such as cough, waking the children. The median time that the children in the present study spent asleep was $9.1 \mathrm{~h}$, about $1 \mathrm{~h}$ shorter than Minde's good sleepers and slightly longer than his poor sleepers. The present study included older children than those in Minde's group.

The large variation in cough counts on nights 1 and 2 suggests a huge night-to-night variation in coughing in children whose parents complain that they have persistent night cough. It is tempting to ask whether "heavy" coughers' sleep improves more with cough reduction than "light" coughers', but it seems unreasonable to label children as "heavy" coughers on data from only 2 nights' recording. From an analysis of night 2 data (between- subject analysis) it can be stated that children who coughed more on that night were more restless and awake. This confirms the general concern of parents that cough disturbs sleep.

It is important to distinguish between variation that is between subjects and that within subjects. The former relates to the question "Do children who cough more on average sleep worse on average?" The latter relates to the question "On a night when a child coughs more than usual, does (s)he sleep worse than usual?" This is what matters for the child and parents. The relationships between cough and time awake, and cough and time awake and restless are extremely weak, suggesting that cough is not likely to cause an alteration in sleep state. If the relationship is, however, assumed to be causal, then for individuals in this study, halving the number of coughs will reduce the time awake by $9 \%$ and so, in real time, those who spend the largest proportion of the night awake will benefit most from the successful treatment of their cough. However, if by poor sleep parents mean a combination of restlessness and being awake, then halving the cough will only improve sleep by $1 \%$ and even the "poorest" sleeper will benefit very little. For this population, efforts to reduce cough would be unlikely to increase significantly the time spent quietly asleep, at least over a two week period.

In conclusion, a reduction in persistent nocturnal cough will not be related to a clinically important reduction in the proportion of the night spent awake and time in restless sleep for the average child, although this could be important for those children with the longest times awake. Parents seem to know when their child has nocturnal cough and most can detect change. However, they cannot say the same about sleep. It is not known whether these results would translate to a population in rural or suburban communities. The number of wakings and time spent asleep compares well with a selected group of children in a university town environment [17] in whom cough was not a complaint. It was not determined whether children with nocturnal cough in different home environments would sleep better when their cough improved. 
Acknowledgements: The authors are grateful to $M$. Healy who kindly helped to analyse the data.

\section{References}

1. Dawson B, Horobin G, Illsley R, Mitchell R. A survey of childhood asthma in Aberdeen. Lancet 1969; i: 827-830.

2. Williams H, McNicol KN. Prevalence, natural history and relationship of wheezy bronchitis and asthma in children: an epidemiological study. $B M J 1969 ; 4$ : 321-325.

3. Phelan P. Asthma in children: epidemiology. BMJ 1994; 308: $1584-1585$.

4. Warner J. Asthma: a follow-up statement from an international paediatric asthma consensus group. Arch Dis Child 1992; 67: 240-248.

5. British Thoracic Society, National Asthma Campaign, Royal College of Physicians of London, et al. British Guidelines on Asthma Management. Review and Position Statement. Thorax 1995; 52: Suppl. 1, S9.

6. Editorial. Cough and wheeze in asthma: are they interdependent? Lancet 1988; i: 447-448.

7. McKenzie SA. Cough - but is it asthma? Arch Dis Child 1994; 70: 1-2.

8. Wright AL, Holberg CJ, Morgan WJ, Taussig LM, Halonen M, Martinez FD. Recurrent cough in childhood and its relation to asthma. Am J Crit Care Med 1996; 153: 1259-1265.

9. Kelly YJ, Brabin BJ, Milligan PJM, Reid JA, Heaf D, Pearson MG. The clinical significance of cough in the diagnosis of asthma in the community. Arch Dis Child 1996; 75: 489-493.
10. Powell CVE, Primhak RA. Stability of respiratory symptoms in unlabelled wheezy illness and nocturnal cough. Arch Dis Child 1996; 75: 1-7.

11. Hoskyns EW, Thomson A, Decker E, Hutchins A, Simpson $\mathrm{H}$. Effect of controlled release salbutamol on nocturnal cough in asthma. Arch Dis Child 1991; 66: 1209-1212.

12. Cornford CS, Morgan M, Ridsdale L. Why do mothers consult when their children cough? Family Practice 1993; 10: 193-196.

13. Archer LNJ, Simpson H. Night cough counts and diary card scores in asthma. Arch Dis Child 1985; 60: 473-474.

14. Thomson A, Pratt C, Simpson H. Nocturnal cough in asthma. Arch Dis Child 1987; 62: 1001-1004.

15. Falconer A, Oldman C, Helms P. Poor agreement between reported and recorded nocturnal cough in asthma. Pediatr Pulmonol 1993; 15: 209-211.

16. Kaplan BJ, McNicol J, Conte RA, Moghadam HK. Sleep disturbance in pre-school-aged hyperactive and non-hyperactive children. Pediatrics 1987; 80: 839-844.

17. Minde K, Popiel K, Leos N, Falkner S, Parker K, HandleyDerry M. The evaluation and treatment of sleep disturbances in young children. J Child Psychol Psychiat 1993; 34: 521-523.

18. Anders TF. Home-recorded sleep in 2 and 9-month old infants. J Am Acad Child Psychol 1978; 17: 421-432.

19. Picciotto A, Hubbard M, Fuller P, McKenzie SA. Videorecording at night in the home. Int J Soc Res Methodol 1998; 1: 153-161.

20. Dahl RE. The impact of inadequate sleep on children's daytime cognitive function. Semin Pediatr Neurol 1996; 3: 44-50. 